\title{
Influence of calcium ion on host cell invasion and intracellular replication by Toxoplasma gondii
}

\author{
Hyun-Ouk SONG ${ }^{1}$, Myoung-Hee $\mathrm{AHN}^{1) *}$, Jae-Sook RYU ${ }^{1)}$, Duk-Young MIN ${ }^{1}$, \\ Kyoung-Hwan JOO ${ }^{2}$ and Young-Ha LEE ${ }^{3)}$ \\ ${ }^{1)}$ Department of Parasitology and Institute of Biomedical Science, Hanyang University College of Medicine, Seoul 133-791 \\ ${ }^{2)}$ Department of Parasitology, Korea University College of Medicine, Seoul 136-701 \\ ${ }^{3)}$ Department of Parasitology, Chungnam National University College of Medicine, Daejeon 301-131, Korea
}

\begin{abstract}
Toxoplasma gondii is an obligate intracellular protozoan parasite, which invades a wide range of hosts including humans. The exact mechanisms involved in its invasion are not fully understood. This study focused on the roles of $\mathrm{Ca}^{2+}$ in host cell invasion and in $T$. gondii replication. We examined the invasion and replication of $T$. gondii pretreated with several calcium modulators, the conoid extrusion of tachyzoites. Calmodulin localization in T. gondii were observed using the immunogold method, and $\mathrm{Ca}^{2+}$ levels in tachyzoites by confocal microscopy. In light microscopic observation, tachyzoites co-treated with A23187 and EGTA showed that host cell invasion and intracellular replication were decreased. The invasion of tachyzoites was slightly inhibited by the $\mathrm{Ca}^{2+}$ channel blockers, bepridil and verapamil, and by the calmodulin antagonist, calmidazolium. We observed that calcium saline containing A23187 induced the extrusion of tachyzoite conoid. By immunoelectron microscopy, gold particles bound to anti-calmodulin or anti-actin $\mathrm{mAb}$, were found to be localized on the anterior portion of tachyzoites. Remarkably reduced intracellular $\mathrm{Ca}^{2+}$ was observed in tachyzoites treated with BAPTA/AM by confocal microscopy. These results suggest that host cell invasion and the intracellular replication of $T$. gondii tachyzoites are inhibited by the calcium ionophore, A23187, and by the extracellular calcium chelator, EGTA.
\end{abstract}

Key words: Toxoplasma gondii, calcium ion, cell invasion, intracellular replication

\section{INTRODUCTION}

Toxoplasma gondii is an apicomplexan protozoa, which can cause abortion or congenital birth defects in humans. Toxoplasma encephalitis has recently emerged as a serious opportunistic infection, especially in association with AIDS (Luft and Remington, 1992; Wong and Remington, 1993). T. gondii invades

- Received 13 October 2004, accepted after revision 18 November 2004.

- This work was supported by Grant No. R01-2002-00000422-0 from Korea Science and Engineering Foundation.

*Corresponding author (e-mail: mhahn@hanyang.ac.kr) host cells at the tachyzoite stage, and tachyzoites within a parasitophorous vacuole rapidly replicate, rupture host cells, and invade new cells (Hall and Joiner, 1991; Dubey et al., 1998). The cell invasion mechanism consists of host cell attachment, protrusion of the conoid, exocytosis of micronemes and rhoptries, and finally membrane penetration (Morisaki et al., 1995). This mechanism involves many factors such as intracellular divalent ions, enzymes, and the cytoskeletal structures of T. gondii (Lee et al., 2002).

The calcium ion $\left(\mathrm{Ca}^{2+}\right)$ is maintained at relatively low concentrations by many channels and pumps in 
cell membranes and cellular organelles. When intracellular calcium is increased due to signal transduction, it interacts with calmodulin or protein kinase $C$ or with other intracellular molecules, to induce a plethora of intracellular processes, including cell motility, division, secretion, cytoskeletal activity, and protein synthesis. Moreover, calcium ion binding proteins such as calmodulin, act as $\mathrm{Ca}^{2+}$ receptors. Calmodulin is a small protein, which binds $\mathrm{Ca}^{2+}$, and the $\mathrm{Ca}^{2+}$-calmodulin complex formed is involved in many signal transduction pathways (Cheung, 1980). On the other hand, the unbound calcium ion is a major signaling molecule in eukaryotic cells, including many human parasitic protozoa, such as Trypanosoma cruzi, Leishmania sp., T. gondii, and Giardia lamblia (Makioka et al., 2001; Moreno and Docampo, 2003). The pretreatment of T. cruzi trypomastigotes with $\mathrm{Ca}^{2+}$ chelator, BAPTA/AM decreased their infectivity while treatment with $\mathrm{Ca}^{2+}$ ionophore, ionomycin enhanced the infectivity (Yakubu et al., 1994). Moreover, when tachyzoites of T. gondii attach and invade host cells, calcium concentrations in the tachyzoites are increased (Mondragon and Frixione, 1996; Vieira and Moreno, 2000).

Therefore, the present experiment was undertaken to determine the influence of $\mathrm{Ca}^{2+}$ in $T$. gondii during host cell invasion and intracellular replication by using calcium modulators and calmodulin antagonist. Moreover, changes of intracellular $\mathrm{Ca}^{2+}$ and calmodulin in tachyzoites were observed by confocal and electron microscopy.

\section{MATERIALS AND METHODS}

\section{Reagents}

RPMI 1640 was purchased from Invitrogen (Carlsbad, CA, USA) and fetal bovine serum from Cambrex (Walkersville, MD, USA). EGTA (ethylene glycol-bis( $\beta$-aminoethyl ether)-N,N,N,N'-tetraacetic acid) was used as an extracellular calcium chelator, BAPTA/AM (1,2-bis(2-aminophenoxy)ethane$\mathrm{N}, \mathrm{N}, \mathrm{N}, \mathrm{N}^{\prime}$-tetraacetic acid) as an intracellular calcium chelator. A23187 was used as a calcium ionophore, thapsigargin as an intracellular calcium store release agent, bepridil and verapamil as calcium channel blockers, and calmidazolium as a calmodulin antagonist. Stock solution of EGTA was prepared in distilled water $(50 \mathrm{mM} / \mathrm{ml})$, and bepridil was prepared in $95 \%$ ethanol $(5 \mathrm{mM} / \mathrm{ml})$. Other drugs were prepared in DMSO (BAPTA/AM, $10 \mathrm{mM} / \mathrm{ml}$; A23187, $5 \mathrm{mM} / \mathrm{ml}$; thapsigargin, $250 \mu \mathrm{M} / \mathrm{ml}$; verapamil, $5 \mathrm{mM} / \mathrm{ml}$; calmidazolium, $1 \mathrm{mM} / \mathrm{ml}$, respectively) and stored at $-20^{\circ} \mathrm{C}$ before use. All calcium modulators and the calmodulin antagonist were obtained from Sigma (St Louis, MO, USA); Fluo-4 AM from Molecular probes (Eugene, OR, USA); LR white from London Resin White (Hants, UK); anti-actin monoclonal antibody from Santa Cruz (Santa Cruz, CA, USA); and anticalmodulin monoclonal antibody from Calbiochem (San Diego, CA, USA).

\section{Parasites}

Tachyzoites of $T$. gondii (RH starin) were propagated by intraperitoneal passage in ICR mice (Daehan Biolink Co., Korea) at 3 or 4 day intervals. After injecting RPMI 1640 intraperitoneally, mouse peritoneal fluid was sampled and centrifuged at $40 \mathrm{~g}$ for $5 \mathrm{~min}$ twice, and then at $650 \mathrm{~g}$ for $10 \mathrm{~min}$. The supernatant was removed and pellets were resuspended in RPMI 1640 at the desired cell density. Parasite viability was determined using trypan blue ( $0.2 \%$ solution).

\section{Invasion assay of $T$. gondii treated with $\mathrm{Ca}^{2+}$ modulators and ionophore}

HeLa cells (a human cervical cancer cell line, Yonsei University) were cultured in a $50 \mathrm{ml}$ culture flask (Becton Dickinson, Franklin Lakes, NJ, USA) in RPMI 1640 supplemented with $10 \%$ fetal bovine serum (RPMI 1640/10\% FBS), and antibiotics $\left(10^{4}\right.$ units of penicillin $/ \mathrm{ml}$ and $10^{4} \mu \mathrm{g}$ of streptomycin $/ \mathrm{ml}$ ) at $37^{\circ} \mathrm{C}$ in a saturated $5 \% \mathrm{CO}_{2}$ atmosphere. Round coverslips were placed over wells in a 12-well plate containing 2 $\mathrm{ml}$ of RPMI $1640 / 10 \%$ FBS. HeLa cells $\left(1 \times 10^{5}\right)$ were then added to each well, and incubated at $37^{\circ} \mathrm{C}$ in a saturated $5 \% \mathrm{CO}_{2}$ atmosphere for $6 \mathrm{hr}$. The effective and lowest concentrations of calcium modulators and calmodulin antagonist were determined. Tachyzoites were separatively incubated with 10 mM EGTA, 25 
$\mu \mathrm{M}$ BAPTA/AM, $1 \mu \mathrm{M}$ A23187, $5 \mu \mathrm{M}$ A23187 with 2 mM EGTA, $5 \mu \mathrm{M}$ thapsigargin, $10 \mu \mathrm{M}$ bepridil, $10 \mu \mathrm{M}$ verapamil, or $1 \mu \mathrm{M}$ calmidazolium, at $37^{\circ} \mathrm{C}$ for $20 \mathrm{~min}$. T. gondii tachyzoites were washed with RPMI 1640 and infected to HeLa cells (parasite:cell = 5:1). The infection rates and mean numbers of tachyzoites in HeLa cells were assessed by counting infected cells and the numbers of tachyzoites in 100 cells, respectively, under a light microscope after stained with $10 \%$ Giemsa solution at $4 \mathrm{hr}$ or $18 \mathrm{hr}$ post infection (PI). Experiments were performed in triplicate and results were averaged.

\section{Conoid extrusion assay}

T. gondii tachyzoites were suspended in normal or calcium saline ( $5 \mathrm{mM} \mathrm{CaCl}_{2}$ ) containing $5 \mu \mathrm{M} \mathrm{A23187,}$ $25 \mu \mathrm{M}$ BAPTA/AM, or $5 \mu \mathrm{M}$ calmidazolium and incubated at $37^{\circ} \mathrm{C}$ for $20 \mathrm{~min}$. After centrifugation, tachyzoites were fixed with $2 \%$ glutaraldehyde for $1 \mathrm{hr}$, resuspended in distilled water, and stained with $10 \%$ Giemsa solution. T. gondii with a extended conoid were counted among 100 tachyzoites under a light microscope.

\section{Immunoelectron microscopy}

T. gondii were treated with $1 \mu \mathrm{M}$ calmidazolium in RPMI 1640 for $1 \mathrm{hr}$, fixed with 2\% glutaraldehyde for $3 \mathrm{hr}$, and then post-fixed with 1\% osmium tetroxide. Specimens were sequentially dehydrated in $20 \%, 50 \%$, $70 \%$ and $100 \%$ ethanol, and embedded in LR white. Ultrathin sections on a nickel grid were incubated with $\mathrm{NH}_{4} \mathrm{Cl}, 0.5 \mathrm{M}$ Tris buffer, and then for $2 \mathrm{hr}$ with anti-calmodulin or anti-actin $\mathrm{mAb}(1: 50)$ as a primary antibody. Colloidal gold $(12 \mathrm{~nm})$ conjugated to goat anti-mouse IgG (1:40) was then added as a secondary antibody. After washing, sections were stained with $4 \%$ uranyl acetate and lead citrate, and observed under an electron microscope (Hithachi H-7600s, Japan).

\section{Confocal microscopy}

T. gondii tachyzoites $\left(2 \times 10^{7}\right)$ in RPMI 1640 were stained with Fluo-4 AM according to the manufacturer's instructions. After treating T. gondii tachyzoites with BAPTA/AM, A23187, or calmidazolium, intracellular calcium of tachyzoites was observed under a confocal microscope (Bio-rad MRC 1024, CA, USA). Briefly, tachyzoites were stained with $10 \mu \mathrm{M}$ Fluo-4 $\mathrm{AM}$ at room temperature for $45 \mathrm{~min}$, washed with phosphate buffered saline (PBS) twice, and then incubated in $1 \mathrm{ml}$ PBS for $30 \mathrm{~min}$. After treating tachyzoites with $50 \mu \mathrm{M}$ BAPTA/AM, $5 \mu \mathrm{M}$ A23187, or $5 \mu \mathrm{M}$ calmidazolium for $20 \mathrm{~min}$, they were examined by confocal microscopy.

\section{Statistical analysis}

The Mann-Whitney U test was used for statistical analysis. All experimental data are presented as means \pm standard deviation. $P$ values less than 0.05 are considered significant and marked with an asterisk $(*)$.

\section{RESULTS}

Cell invasion of T. gondii was reduced by treating with calcium modulators or calmodulin antagonist

To determine the role of $\mathrm{Ca}^{2+}$ on host cell invasion and T. gondii replication, tachyzoites were treated with the calcium modulators, EGTA, BAPTA/AM, A23187, thapsigargin, bepridil, verapamil, or with the calmodulin antagonist, calmidazolium. Invasion into HeLa cells was greatly reduced by treating $T$. gondii with $5 \mu \mathrm{M}$ A23187 and $2 \mathrm{mM}$ EGTA at $4 \mathrm{hr}(20.0 \pm$ $4.2 \%$, untreated $32.1 \pm 4.1 \%)$ and at $18 \mathrm{hr}(29.1 \pm 3.2 \%$, untreated $43.3 \pm 3.8 \%$ ) PI (Fig. 1). HeLa cell invasion was also suppressed by treating tachyzoites with 25 $\mu \mathrm{M}$ BAPTA/AM or $1 \mu \mathrm{M}$ calmidazolium, and by A23187 or thapsigargin, which showed similar decreased patterns of infectivity $(P<0.05)$ (Fig. 1$)$. The infection rate of HeLa cells by bepridil or verapamil treated tachyzoites did not change at $4 \mathrm{hr}$ PI. Intracellular replication of T. gondii in HeLa cells was slightly suppressed by $\mathrm{Ca}^{2+}$ modulators $(P<0.05)$ (Fig. 2$)$.

\section{Calcium saline with calcium ionophore induced conoid extrusion of $T$. gondii}

The rates of conoid extrusion after treating tachy- 


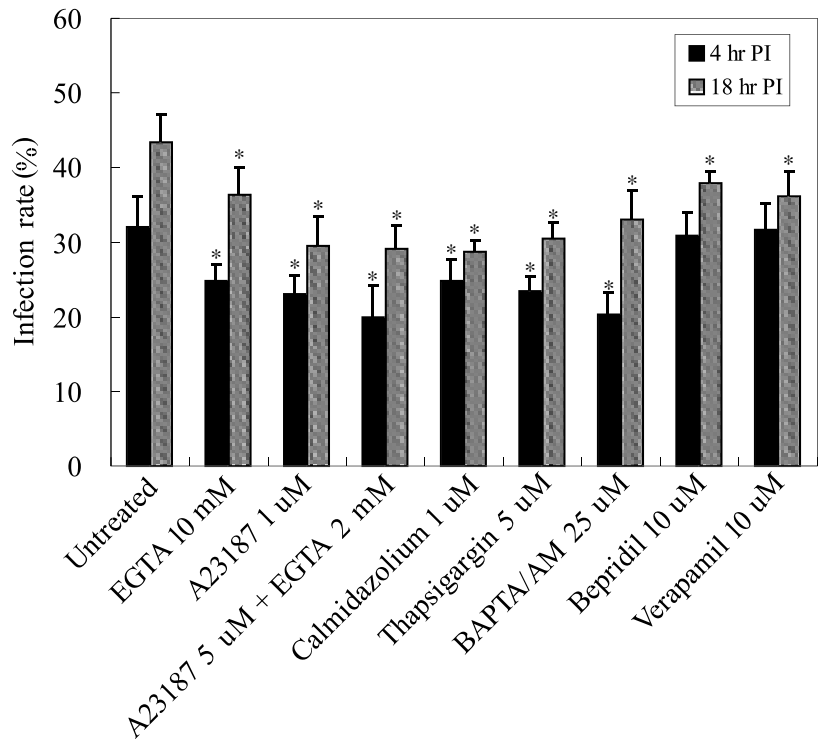

Fig. 1. Infection rates of $T$. gondii tachyzoites pre-incubated with various calcium modulators and calmodulin antagonist. Tachyzoites were treated with calcium modulating drugs for $20 \mathrm{~min}$ at $37^{\circ} \mathrm{C}$ before HeLa cell infection. Cell invasion by $T$. gondii was observed at $4 \mathrm{hr}$ and $18 \mathrm{hr}$ postinfection under a light microscope after Giemsa staining. ${ }^{*} P<0.05$.

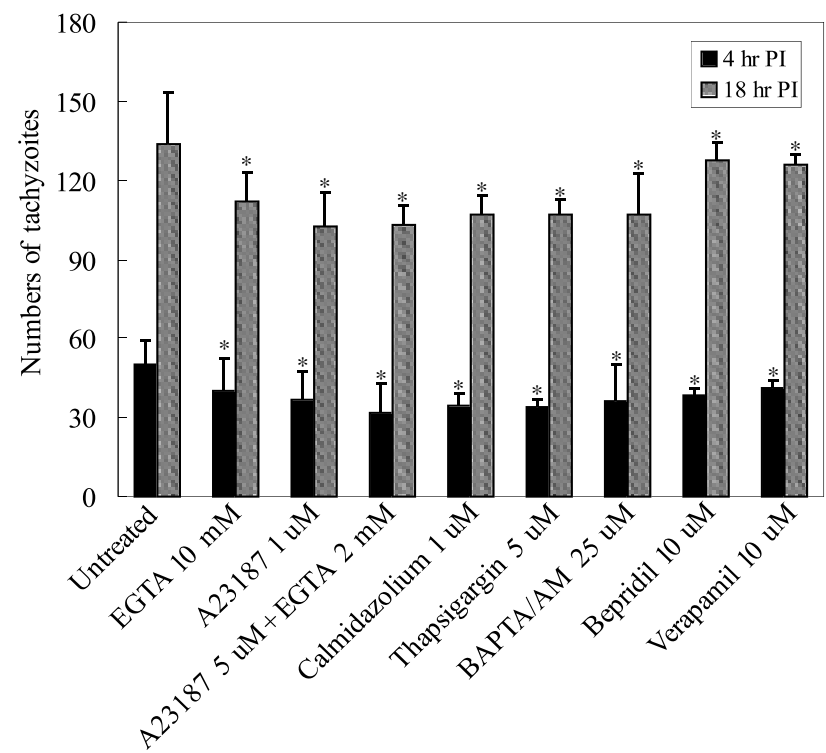

Fig. 2. The numbers of tachyzoite in 100 HeLa cells infected with $T$. gondii which had been pre-incubated with various calcium modulators and calmodulin antagonist and then infected with T. gondii. Intracellular tachyzoites were counted at $4 \mathrm{hr}$ and $18 \mathrm{hr}$ post-infection under a light microscope after Giemsa staining. ${ }^{*} P<0.05$.
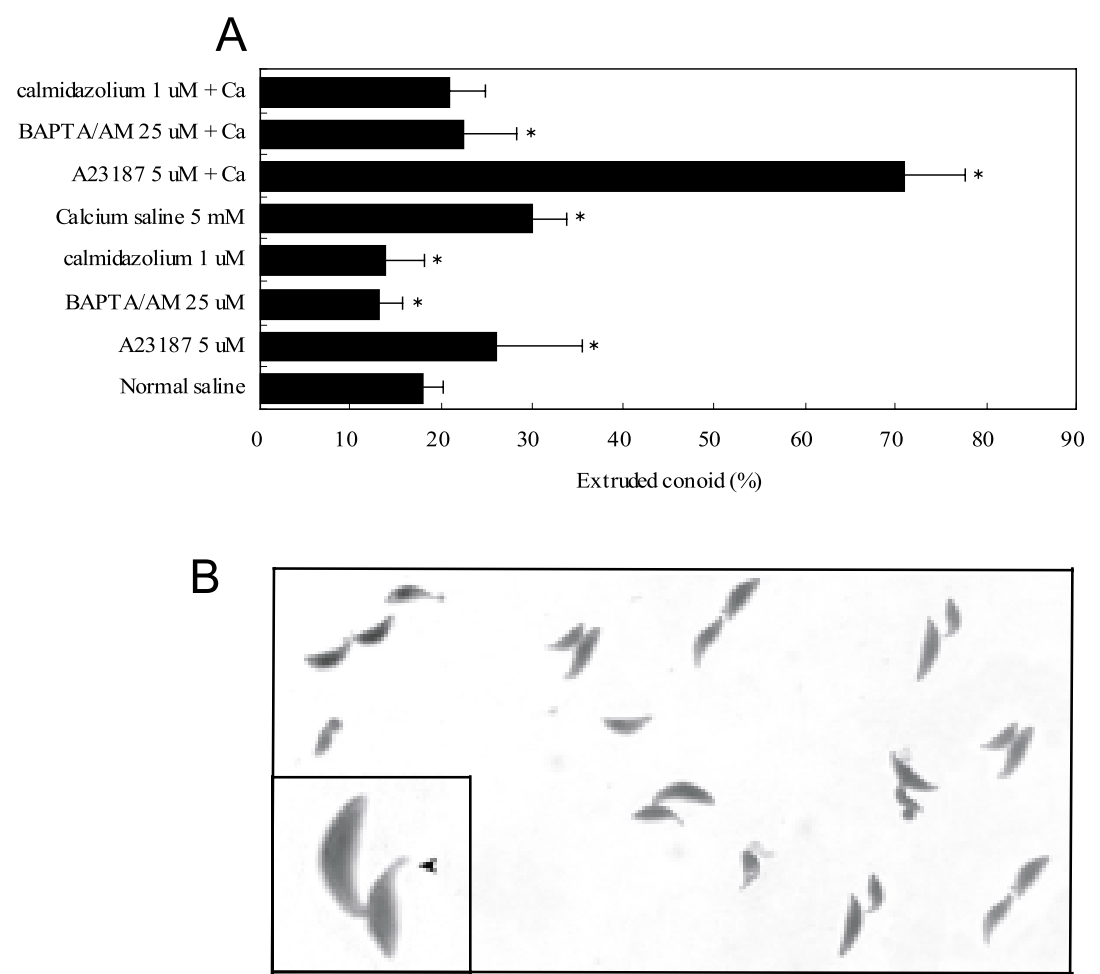

Fig. 3. A. Conoid extrusion rates of $T$. gondii tachyzoites in calcium saline $(5 \mathrm{mM})$ or normal saline containing A23187, BAPTA/AM, or calmodulin were counted under a light microscope. B. An extruded conoid (arrowhead) after incubation in calcium saline containing A23187, $\times 400$ (inset, $\times 2,000$ ). 


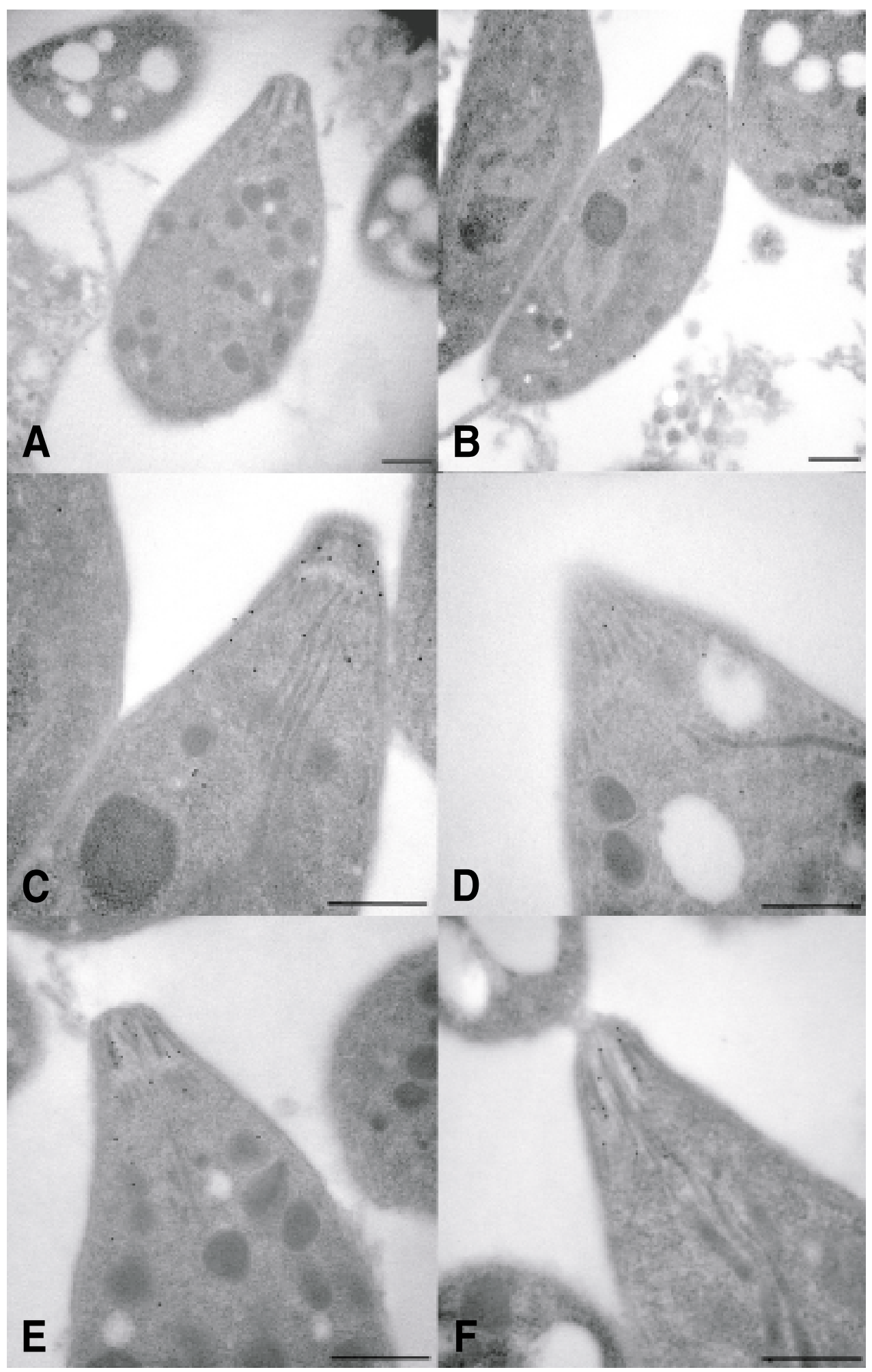

Fig. 4. The localization of calmodulin and actin in T. gondii. Tachyzoites were observed by electron microscopy after labeling with anti-calmodulin (B, C, and D), anti-actin (E, F) monoclonal antibodies, and gold particles (12 nm) conjugated with anti-mouse IgG antibody. Tachyzoites were pretreated with calmidazolium (D, F) for 20 min before monoclonal antibody labeling. Tachyzoites treated with gold conjugated anti-mouse IgG were used as a control (A). Scale bar $=0.1$ $\mu \mathrm{m}$. 


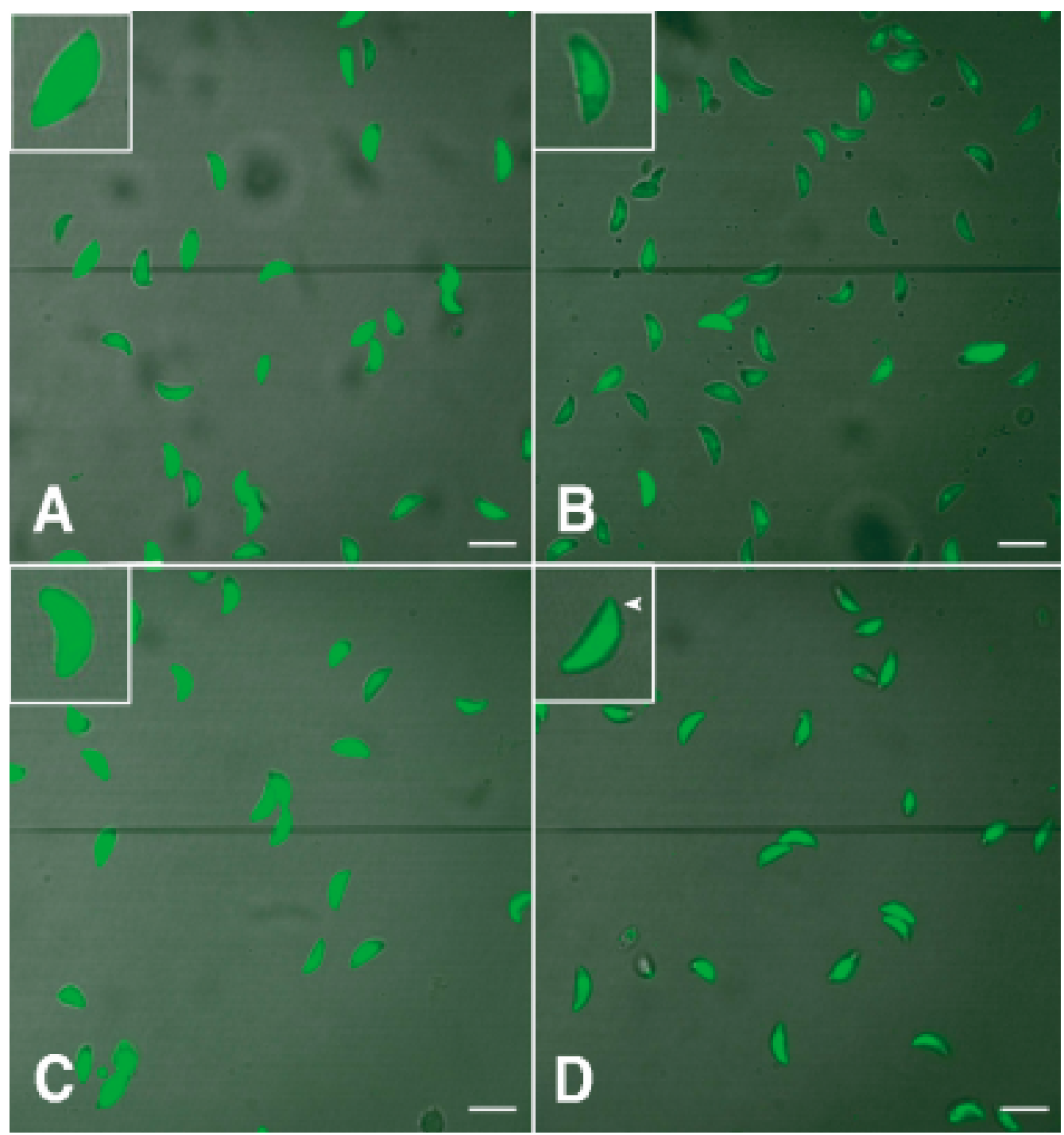

Fig. 5. Confocal microscopic observations of calcium in the cytoplasm of $T$. gondii tachyzoites treated with calcium modulators or calmodulin antagonist $(\times 400$; inset: $\times 2,000$ ). Untreated (A), $50 \mu \mathrm{M}$ BAPTA/AM (B), $5 \mu \mathrm{M}$ A23187 (C), or $5 \mu \mathrm{M}$ calmidazolium (D) treated tachyzoites are shown. In calmodulin treated tachyzoites, calcium ions were reduced especially in the anterior region (arrowhead, D). Scale bar $=10 \mu \mathrm{m}$.

zoites with calcium and A23187 were evaluated by light microscopy after Giemsa staining. The exposure of tachyzoites to calcium saline containing $5 \mu \mathrm{M}$ A23187 for 20 min induced conoid extrusion in $71.0 \pm$ $6.7 \%$ (normal saline $17.8 \pm 2.4, P<0.05$ ) (Fig. 3 ). The conoid extrusion percentage of tachyzoites in normal saline containing A23187 was lower than in calcium saline containing A23187. However, tachyzoites treatment in calcium saline containing BAPTA/AM or calmidazolium did not induce conoid extrusion (Fig. 3A).

\section{Calmodulin was localized on the anterior por- tion of tachyzoites}

Calmodulin localization in T. gondii was observed by immunoelectron microscopy. When $T$. gondii was labeled with anti-calmodulin $\mathrm{mAb}$ and colloidal gold $(12 \mathrm{~nm})$ conjugated with goat anti-mouse IgG, gold particles were found to be localized at the apical region of tachyzoites (Figs. 4B, 4C). On the other hand, calmodulin antagonist calmidazolium treated tachyzoites showed few gold particles (Fig. 4D). The 
actin of T. gondii was localized at the anterior portion of tachyzoites by anti-actin mAb (Figs. 4E, 4F). Calmodulin and actin were not observed in regions other than the anterior portion of $T$. gondii tachyzoites. Therefore, calmodulin and actin were found colocalized in the apical region of tachyzoites.

\section{Change of calcium in $T$. gondii was observed after calcium chelator treatment}

Tachyzoites were treated with $50 \mu \mathrm{M}$ BAPTA/AM, $5 \mu \mathrm{M}$ A23187, or $5 \mu \mathrm{M}$ calmidazolium for $20 \mathrm{~min}$, respectively, and examined under a confocal microscope. Tachyzoites treated with BAPTA/AM showed a distinct reduction in cytoplasmic calcium (Fig. 5B). Calmidazolium-treated tachyzoites showed slightly reduced intracellular calcium levels, especially in the apical region, but no significant efflux of calcium were observed from A23187-treated tachyzoites (Figs. 5C, $5 \mathrm{D})$.

\section{DISCUSSION}

The invasion of host cells by T. gondii involves complex mechanisms such as conoid extrusion, cytoskeletal rearrangement, and the secretion of proteins and enzymes (Morisaki et al., 1995; Black et al., 2000). Extracellular and intracellular $\mathrm{Ca}^{2+}$ play an important role during invasion, conoid extrusion, and intracellular replication (Hupe et al., 1991; Mondragon and Frixione, 1996; Bonhomme et al., 1999). In this study, extracellular and intracellular calcium chelators, calcium ionophore, calcium channel blockers, and calmodulin antagonist were used to reduce the $\mathrm{Ca}^{2+}$ in $\mathrm{T}$. gondii. When tachyzoites were co-treated with the $\mathrm{Ca}^{2+}$ ionophore A23187 and calcium chelator EGTA, invasion into HeLa cells was reduced at $4 \mathrm{hr}$ and $18 \mathrm{hr}$ PI. Treatment of A23187 and EGTA effectively suppressed tachyzoite invasion compared to tachyzoites treated with A23187 or EGTA alone. However, the calcium channel blockers, bepridil or verapamil, were less effective at inhibiting invasion (Figs. 1, 2). These results suggest that treatment with a calcium ionophore and an extracellular $\mathrm{Ca}^{2+}$ chelator lead to $\mathrm{Ca}^{2+}$ efflux in T. gondii and inhibited cell invasion.
When tachyzoites were treated with A23187 or ionomycin as calcium ionophores, loss of infectivity and conoid extrusion were reported (Mondragon and Frixione, 1996; Pezzella et al., 1997; Black et al., 2000).

Intracellular calcium levels in $T$. gondii were reduced by BAPTA/AM and invasion was inhibited by reducing calcium in parasite (Mondragon and Frixione, 1996). In our experiment, HeLa cell invasion was significantly inhibited by BAPTA/AM treated tachyzoites at $4 \mathrm{hr}$ and $18 \mathrm{hr} \mathrm{PI}$ and reduced $\mathrm{Ca}^{2+}$ was observed in the cytoplasm of tachyzoites by confocal microscopy (Figs. 1, 2, 5B). When tachyzoites were pretreated with the extracellular calcium chelator EGTA, T. gondii invasion and intracellular replication were slightly reduced versus intracellular calcium chelator pretreatment (Figs. 1, 2). In case of tachyzoites pretreated with thapsigargin, an intracellular calcium store releaser, conoid extrusion was observed presumably due to the release of intracellular calcium (Mondragon and Frixione, 1996). Moreover, we observed that thapsigargin pretreated tachyzoites showed reduced HeLa cell invasion at $4 \mathrm{hr}$ and $18 \mathrm{hr}$ PI (Figs. 1, 2). The cytoskeleton of T. gondii is known to take a part in host cell invasion, and dependency of cytoskeletal alteration on calmodulin have been described in Plasmodium falciparum (Matsumoto et al., 1987; Lee et al., 2002). Calcium-calmodulin complexes have several known functions, i.e., the assembly and disassembly of microtubules, and in cell motility, secretion, metabolism, and growth (Ray et al., 1990; Pezzella et al., 1997). When calmidazolium pretreated tachyzoites were added to HeLa cells, infection rates and the numbers of tachyzoites were reduced at $4 \mathrm{hr}$ and $18 \mathrm{hr}$ PI, as were intracellular calcium levels, especially in the apical region of tachyzoites by confocal microscopy (Figs. 1, 2, 5D). We observed that higher concentrations of calcium modulators $(50 \mathrm{mM}$ EGTA, $50 \mu \mathrm{M}$ BAPTA/AM, or $5 \mu \mathrm{M}$ A23187) suppressed the infectivity and intracellular replication of T. gondii. However, no significant differences of host cell invasion and the replication of tachyzoites at high or low concentrations of thapsigargin, bepridil, verapamil, or calmidazolium were observed (data not shown). The infection rate of tachyzoites treated with 
BAPTA/AM or EGTA were increased, but that of calmidazolium-treated tachyzoites did not increase after $18 \mathrm{hr}$ cultivation. Moreover, intracellular $T$. gondii $\mathrm{Ca}^{2+}$ levels could be recovered from the extracellular medium, and thus tachyzoite $\mathrm{Ca}^{2+}$ levels may be elevated in tachyzoites treated with BAPTA/AM or EGTA at $18 \mathrm{hr}$ PI.

In coccidia such as T. gondii, the conoid facilitates host cell invasion (Nichols and Chiappino, 1987). Calcium ion release from internal stores may act as a key signal to activate conoid extrusion, which is probably mediated by actin filaments. In the present study, conoid extruded tachyzoite numbers were increased by incubation with the calcium ionophore, A23187, in $5 \mathrm{mM}$ calcium saline, but BAPTA/AM and calmidazolium did not affect conoid extrusion (Fig. 3). It is considered that the intracellular $\mathrm{Ca}^{2+}$ of $T$. gondii was increased in calcium saline containing A23187, and thus, affected the conoid extrusion. The relationship between passively forced conoid extrusion and infectivity of $T$. gondii would be investigated.

The actin and myosin filaments that influence the motilities of tachyzoites are also located at the apical pole, and calmodulin is located at the anterior region of $T$. gondii tachyzoites during the extracellular state (Pezzella-D'Alessandro et al., 2001). In our experiment, calmodulin and actin were observed at the anterior end of tachyzoites (Figs. 4C, 4E). When T. gondii were treated with the calmodulin antagonist calmidazolium, gold particles decreased in the anterior region (Fig. 4D). Thus, we speculate that the calcium-calmodulin complex contributes to the movement of T. gondii.

The calcium ion is stored in the endoplasmic reticulum, mitochondria, and in the nucleus of eukaryotic cells. In protozoa, including $T$. gondii, another acidic $\mathrm{Ca}^{2+}$ storage organelle, the acidocalcisome, is present in the cytoplasm (Moreno and Zhong, 1996). The calcium storage and homeostasis system of $T$. gondii appears to be similar to that of other eukaryotic cells (Philosoph and Zilberstein, 1989; Bode and Netter, 1996). The calcium ion of host cells also influences cellular replication and the egress of T. gondii tachyzoites (Hupe et al., 1991; Pingret et al., 1996; Moudy et al., 2001). Moreover, when T. gondii contacts a host cell,
$\mathrm{Ca}^{2+}$ signals can stimulate the host cell nucleus to synthesize proteins essential for $T$. gondii replication (Schwartzman and Pfefferkorn, 1982).

The results of the present study suggest that intracellular $\mathrm{Ca}^{2+}$ changes in T. gondii, especially due to calcium ionophores and extracellular calcium, are involved in the invasion and intracellular replication of $T$. gondii, and further suggest that calmodulin, which is located in anterior portion of T. gondii tachyzoites, might also be related to host cell invasion. The influence of the intracellular $\mathrm{Ca}^{2+}$ depletion of host cells on the infectivity of $T$. gondii requires further study.

\section{REFERENCES}

Black MW, Arrizabalaga G, Boothroyd JC (2000) Ionophoreresistant mutants of Toxoplasma gondii reveal host cell permeabilization as an early event in egress. Mol Cell Biol 20: 9399-9408.

Bode HP, Netter KJ (1996) Agonist-releasable intracellular calcium stores and the phenomenon of store-dependent calcium entry. A novel hypothesis based on calcium stores in organelles of the endo- and exocytotic apparatus. Biochem Pharmacol 51: 993-1001.

Bonhomme A, Bouchot A, Pezzella N, Gomez J, Le Moal H, Pinon JM (1999) Signaling during the invasion of host cells by Toxoplasma gondii. FEMS Microbiol Rev 23: 551561.

Cheung WY (1980) Calmodulin plays a pivotal role in cellular regulation. Science 207: 19-27.

Dubey JP, Lindsay DS, Speer CA (1998) Structures of Toxoplasma gondii tachyzoites, bradyzoites, and sporozoites and biology and development of tissue cysts. Clin Microbiol Rev 11: 267-99.

Hall BF, Joiner KA (1991) Strategies of obligate intracellular parasites for evading host defences. Immunol Today 12: 22-27.

Hupe DJ, Pfefferkorn ER, Behrens ND, Peters K (1991) L651, 582 inhibition of intracellular parasitic protozoal growth correlates with host-cell directed effects. J Pharmacol Exp Ther 256: 462-467.

Lee SH, Lee BY, Min DY, Kim JM, Ahn MH (2002) Role of cytoskeleton in host cell invasion by intracellular protozoa Toxoplasma gondii. J Microbiol Biotechnol 12: 628-634.

Luft BJ, Remington JS. (1992) Toxoplasmic encephalitis in AIDS. Clin Infect Dis 15: 211-222. 
Makioka A, Kumagai M, Ohtomo H, Kobayashi S, Takeuchi $\mathrm{T}$ (2001) Effect of calcium antagonists, calcium channel blockers and calmodulin inhibitors on the growth and encystation of Entamoeba histolytica and E. invadens. Parasitol Res 87: 833-837.

Matsumoto Y, Perry G, Scheibel LW, Aikawa M (1987) Role of calmodulin in Plasmodium falciparum: implications for erythrocyte invasion by the merozoite. Eur J Cell Biol 45: 36-43.

Mondragon R, Frixione E (1996) $\mathrm{Ca}^{2+}$-dependence of conoid extrusion in Toxoplasma gondii tachyzoites. J Eukaryot Microbiol 43: 120-127.

Moreno SN, Docampo R (2003) Calcium regulation in protozoan parasites. Curr Opin Microbiol 6: 359-364.

Moreno SN, Zhong L (1996) Acidocalcisomes in Toxoplasma gondii tachyzoites. Biochem J 15: 655-659.

Morisaki JH, Heuser JE, Sibley LD (1995) Invasion of Toxoplasma gondii occurs by active penetration of the host cell. J Cell Sci 108: 2457-2464.

Moudy R, Manning TJ, Beckers CJ (2001) The loss of cytoplasmic potassium upon host cell breakdown triggers egress of Toxoplasma gondii. J Biol Chem 276: 41492-41501.

Nichols BA, Chiappino ML (1987) Cytoskeleton of Toxoplasma gondii. J Protozool 34: 217-226.

Pezzella-D'Alessandro N, Le Moal H, Bonhomme A, et al. (2001) Calmodulin distribution and the actomyosin cytoskeleton in Toxoplasma gondii. J Histochem Cytochem
49: 445-454.

Pezzella N, Bouchot A, Bonhomme A, et al. (1997) Involvement of calcium and calmodulin in Toxoplasma gondii tachyzoite invasion. Eur J Cell Biol 74: 92-101.

Philosoph H, Zilberstein D (1989) Regulation of intracellular calcium in promastigotes of the human protozoan parasite Leishmania donovani. J Biol Chem 264: 10420-10424.

Pingret L, Millot JM, Sharonov S, Bonhomme A, Manfait M, Pinon JM (1996) Relationship between intracellular free calcium concentrations and the intracellular development of Toxoplasma gondii. J Histochem Cytochem 44: 1123-1129.

Ray A, Quade J, Carson CA, Ray BK (1990) Calcium-dependent protein phosphorylation in Babesia bovis and its role in growth regulation. J Parasitol 76: 153-161.

Schwartzman JD, Pfefferkorn ER (1982) Toxoplasma gondii: purine synthesis and salvage in mutant host cells and parasites. Exp Parasitol 53: 77-86.

Vieira MC, Moreno SN (2000) Mobilization of intracellular calcium upon attachment of Toxoplasma gondii tachyzoites to human fibroblasts is required for invasion. Mol Biochem Parasitol 106: 157-162.

Wong SY, Remington JS (1993) Biology of Toxoplasma gondii. AIDS 7: 299-316.

Yakubu MA, Majumder S, Kierszenbaum F (1994) Changes in Trypanosoma cruzi infectivity by treatments that affect calcium ion levels. Mol Biochem Parasitol 66: 119-125. 
